\title{
INDWELLING ACRYLIC PROSTHESIS AFTER POST-NASAL EPTHELIAL INLAY "I.
}

\author{
Dr. P. N. Gutgutia, M.B., B.S., (PAT).
}

Post-nasal epthelial inlay followed by retrograde bone graft has become a standard procedure for cases of depressed nose such as caused by leprosy, syphilis, and some other less common conditions. The epthelial inlay provides the missing lining in such cases and the problems of support of the bridge and tip of the nose is solved by a retrograde bone graft (ANTIA 1959).

Such a bone graft has to be tunnelled between the new skin grafted lining and skin cover of the nose and is fixed to the nasal bones. In some cases of leprosy, the nasal bones are so greatly absorbed that to get anchorage for adequate fixation for the graft is difficult. In some cases the lining and covering skin is so thin that chances of button holing is great which may lead to exposure of the graft and subsequent absorption.

These cases are not ideal for bone grafting. We have tried to solve this problem by an acrylic prosthesis which is simple in making, cheap and gives adequate support. We recommend even the routine use after epithelial inlay if the patient is agreeable to the permanent wearing of such a prosthesis.

Similar prosthesis has been used by L. R. MCLAREN (1958) for syphilitic depressed noses. Our aim in this paper is to impress the fact that such a prosthesis is very easy to make and a junior member of the staff or technician can be trained to make it.

It will be worthwhile here to point out that the inlay cavity should be carried up to the root of the nose in front of the nasal bones. If the nasal bones are very prominent they should be taken off at the top. This ensures that the whole bridge line is supported in continuity by the prosthesis providing an even contour, rather than the upper part being supported by the nasal bones and the lower part by the prosthesis. This often leaves a distinct notch in the dorsal line at the junction of the nasal bones and the prosthesis. The oro-nasal fistula should be made slightly wider than the base of the alae so that introduction of the prosthesis is easy.

\section{Technique}

First a gutta-percha mould is prepared to give the required shape to the nose. Gutta-percha is a latex rubber compound, supplied in the form of sticks of sheets. We prefer the black variety in sheet form. It becomes soft when put in hot water and can be moulded into the desired shape. Chilled water helps to harden it quickly - about 30 cubic $\mathrm{cm}$. of the gutta-percha is put in hot water. When it becomes soft it is introduced into the cavity through 


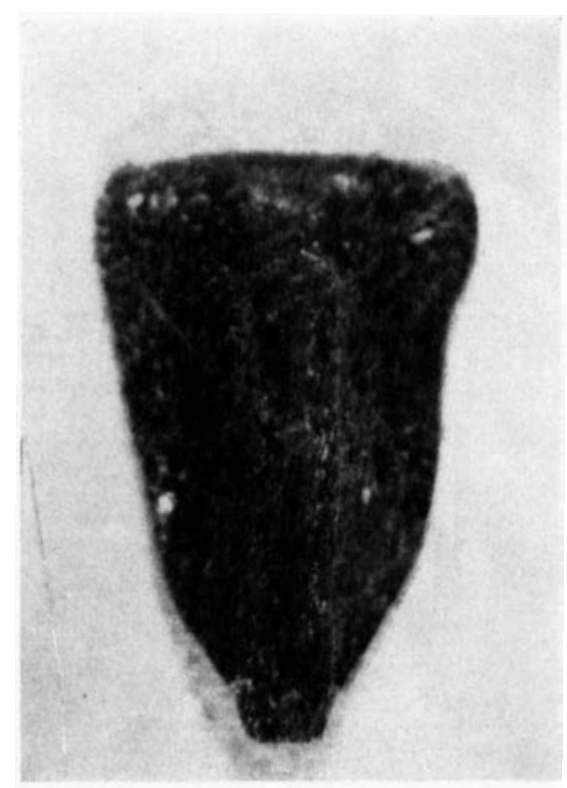

FIG. I. Gutta-percha prosthesis (fromt vie'w).

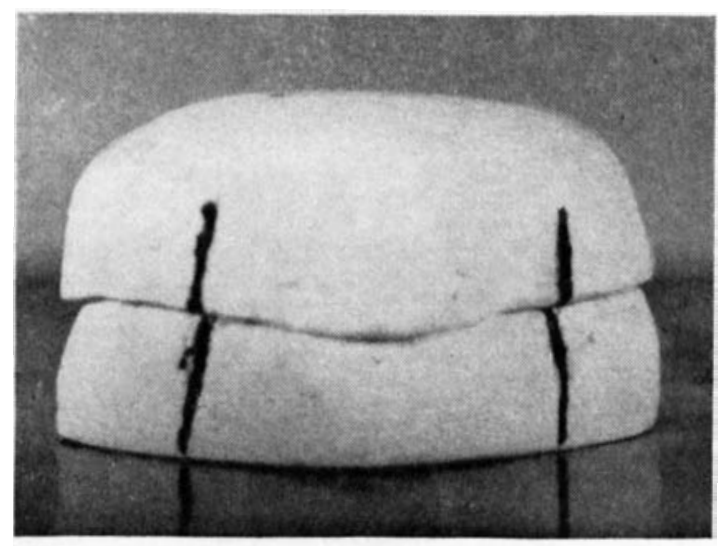

FIG. 3. Gutta-percha prosthesis completely' embedded in plaster-of-paris.

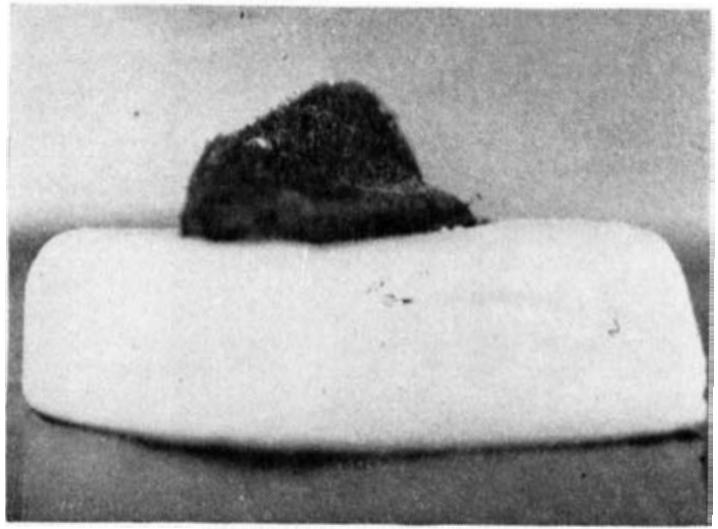

FIG. 2. Gutta-percha prosthesis half embedded in plaster-of-paris.

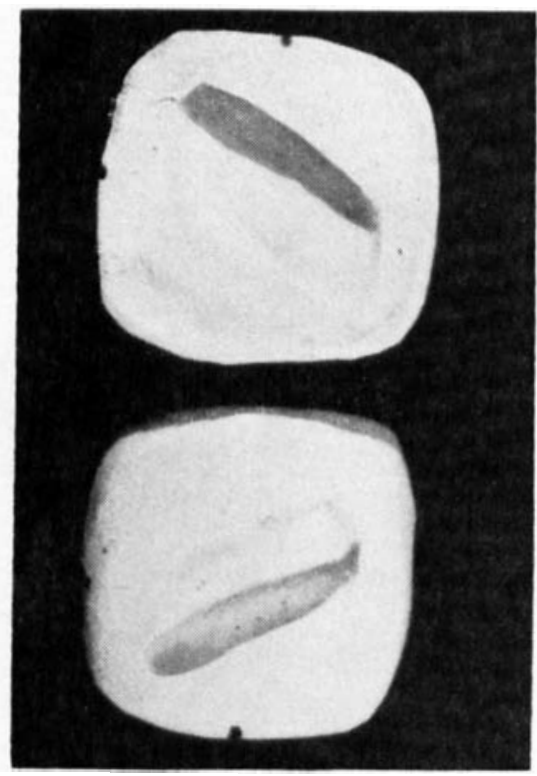

FIG. 4. Plaster-of-paris negative in two halves. 


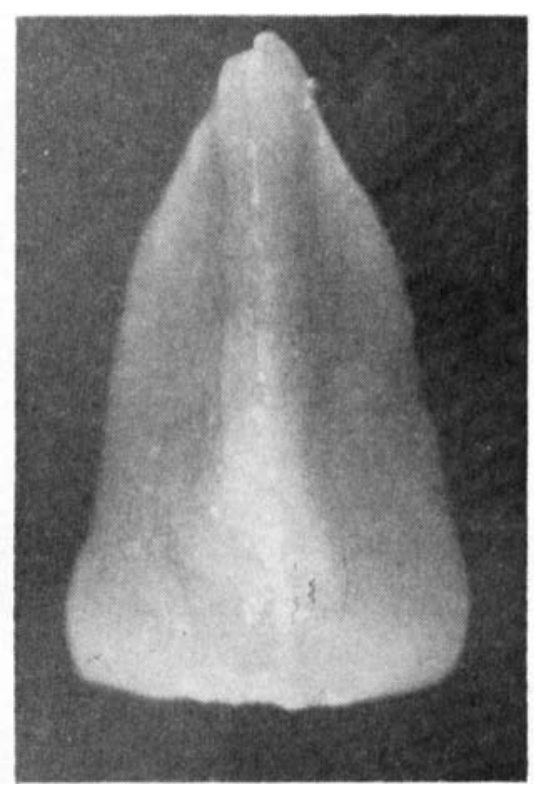

FIG. 5. Acrylic prosthesis.

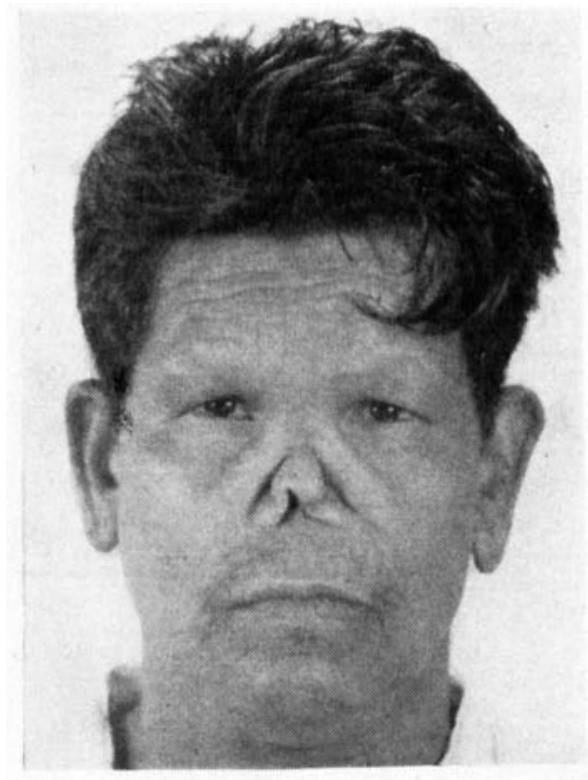

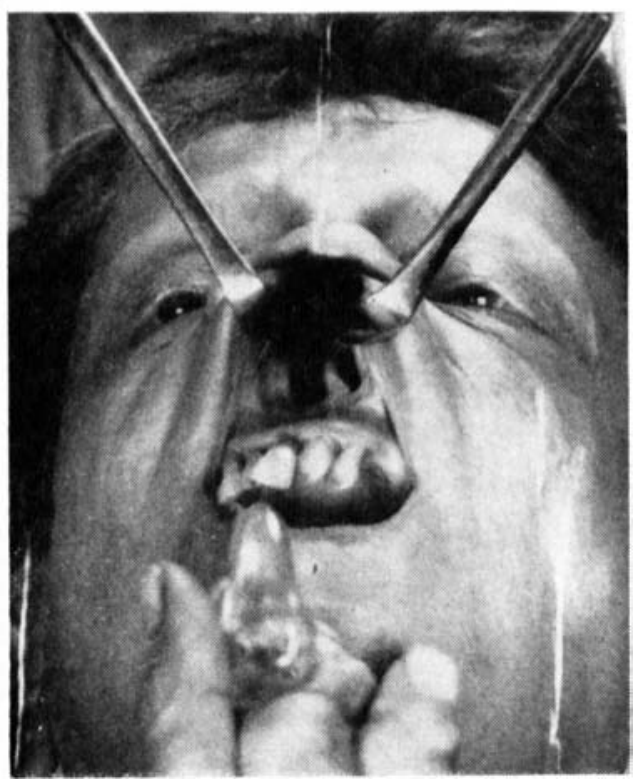

Fig. 6. Showing the post-nasal inlay cavity with the prosthesis in the mutilated hands of the patient.

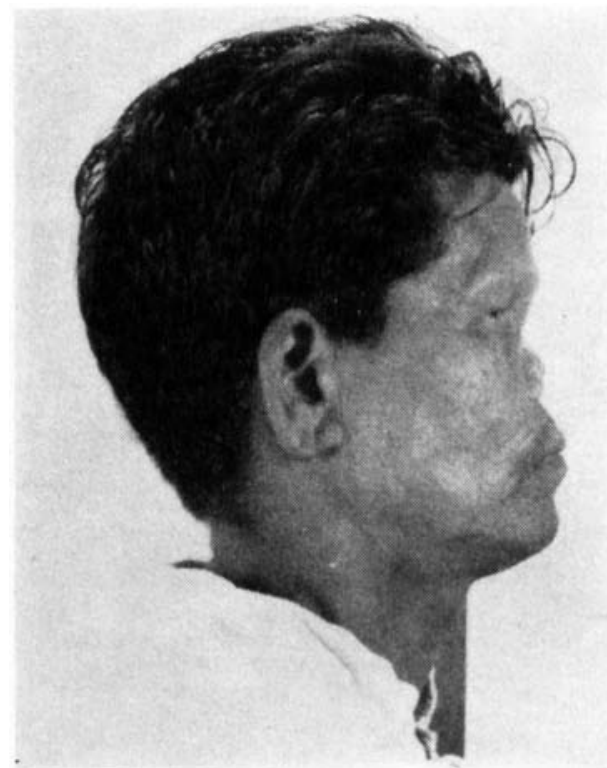

FIG. 7 and 8. Pre-operative appearance of a case. 

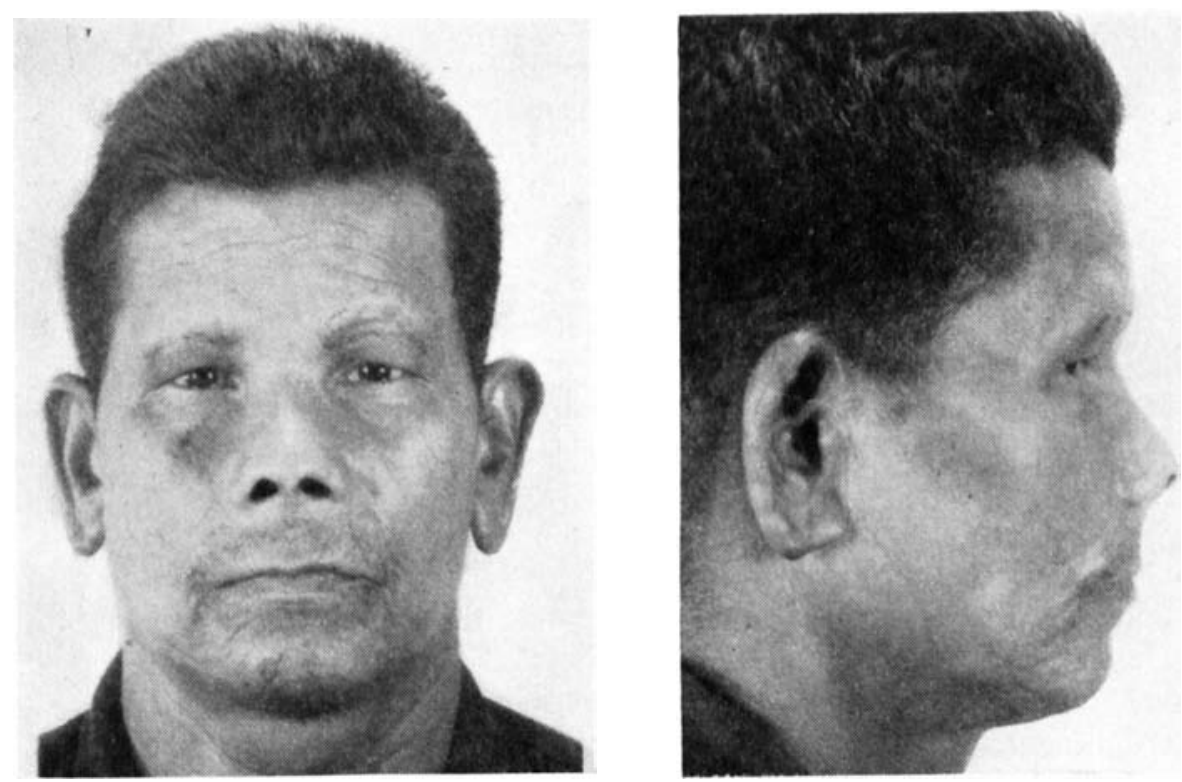

Fig. 9 and 10. Post-operative appearance of the same case with the prosthesis.

the oro-nasal fistula. By external pressure the gutta-percha is moulded so as to give the nose the desired shape. When it hardens it is taken out of the cavity and the sides of the vertical limb of the mould are scraped out by a knife to allow for the normal air way (Fig. 1).

This mould is now converted into an acrylic-prosthesis. Normal acrylic is hot-curing and has to be processed under controlled temperature. This is a complicated dental process. The other variety is cold curing acrylic which is supplied in the form of powder and liquid. When the two are mixed, it sets in 15 minutes. We prefer this type of acrylic for technical simplicity.

The next step is to make a negative of the gutta-percha mould in plaster of paris. About an ounce of water is taken in a rubber bowl. Plaster of paris powder is added to it to make a thick paste which is poured on to a flat surface. The gutta-percha mould is smeared with vaseline and is embedded half into the paste. The paste is then made into a nice square platform with half the mould embedded in it (Fig. 2). When the plaster hardens the upper surface of it and the mould are again smeared with vaseline. More plaster of paris paste is prepared and poured over the mould and the upper surface of the plaster. Care is taken that no air is trapped in. When the plaster hardens, the corresponding points of the two halves of the plaster is marked by a pencil in both dimensions (Fig. 3) and the two halves separated. The gutta-percha mould is now removed from the plaster by dipping in boiling water. The negative in two 
halves is now ready (Fig. 4). The inside of the negative is coated with a layer of 'separating media'. The liquid component of the coldcuring acrylic is poured in to both halves of the negative to which the acrylic powder is gradually added. The cavities in both halves of the negatives are filled in slight excess by pouring alternately the liquid and the powder. The two halves are now pressed together, pencil marks being used as the guide to correct positioning. After 20 minutes (Fig. 5) the two halves are separated and the acrylic prosthesis is taken out.

A small file is used to rub-off the irregularities on the surface of the prosthesis and also for minor adjustments for it to fit the nose properly.

The air passages of the nose communicate with the extcrnal nares through the space formed by the lateral wall of the nose and the vertical limb of the prosthesis, and so there is no difficulty in breathing.

The patient himself takes out this prosthesis daily, cleans it with soap and water and re-introduces it. The oro-nasal fistula is kept open for the purpose. If the patient finds difficulty in introducing the prosthesis because of the deformity of his hands, a small wire loop is introduced into the base of the prosthesis.

This work was done in the Plastic Surgery Department of Sir J. J. Group of Hospitals, Bombay, under the kind guidance of Dr. N. H. Antia, M.B., F.R.C.S. The patients shown in the photographs No. 6 to 10 have been operated on by him. I wish to express to him my heartfelt and grateful thanks.

I acknowledge my gratitude to Mr. H. D. Shaikh, M.D.S., of Sir C. E. M. Dental College, Bombay, who showed the methods of conversion of the gutta-percha mould into acrylic prosthesis.

References

Antia, N. H., 1959 - Transactions of International Society of Plastic Surgeons, p. 547.

Antia, N. H., 1962 - Annals of The Royal College of Surgeons, England, (under publication). 